\title{
On A Criminal Trace of Crippling and Often Even Lethal False Diagnosis: Lege Artis Cz
}

\author{
Antonín Cuc* \\ Czech Technical University Prague CZ, International expert in H+S Medical Devices, Europe
}

Received: 制 April 30, 2018; Published: 盋 May 11, 2018

*Corresponding author: Antonín Cuc, Czech Technical University Prague CZ, International expert in H+S Medical Devices, Europe

\section{Case Report}

In 2010, the Czech Republic participated in the World Health Organization WHO Research to determine the quality of medical decision making in determining diagnosis and to determine an adequate individual choice of patient treatment. The conclusions were really frightening: the relative frequency of fatal medical decision-making errors is $10 \%$, with a statistical accuracy of the tolerance estimate of $+/-2 \%$, with a statistical reliability of conclusions of about 95\%. Approximately rewarding results are found in all OECD countries - in all types of outpatient or inpatient health services. In real terms, this means that approximately every 10 th accidental visit of the patient to the doctor will end up with an additional health problem. For example, a late-diagnosis of B-type jaundice, a medical prescription of an inappropriate medication that contravenes the health of a particular patient, or contraindicates the contraindication effects of other concurrent medications, or a radiologist misinterprets an X-ray image-with overlooked by emerging stomach cancer, overlooked severely fatal osteoporosis-disturbed bone, a preventive standard examination of the colonoscopy will occur with careless medical manipulation of the colon perforation probe in a hitherto healthy patient. In general, they are seriously threatened patients, sometimes even seriously endangered patient lives.

If the above mentioned documented WHO research results refer to the whole Czech pupil - that is, for the total population of the Czech Republic, 10.6 million living people and an average of at least one annual patient visit to any doctor in the Czech Republic. approximately 1 million citizens are probable expected to be expected to receive approximately one million people instead of the actual assistance needed in the Diagnosis and appropriate individual treatment, likely to have an unexpected, addictive crippling health risky next complication - and some patients even due to a deteriorated health condition, probably some of them die sooner - many years before the bio statistic mean survival estimate for the remaining years would be the same-if the medical error did not become the correct diagnosis or treatment. The Providers Health care and medical staff said: It is fatal legal yearly irrevocable Facts - but I have said NO!

On a Criminal Trace of Repeated Mass Medical Mistakes With False Coded Working with Regards Lege Artis CZ

\section{The First Criminal suspicious for Mass Illegal Medical Workflow CZ}

If approximately one million Patients CZ are seriously threatened annually with incorrect medical decision-making contrary medical Knowledge's WHO, logically at least Sum 50,000 Patients CZ are unnecessarily mutilated yearly. They are mostly casual preliminary dying - a long time ago from the adequate Cluster with similar Patients CZ with the same Diagnoses, Age, similar variant of Treatments they are growing differenced Health consequences and ever-increasing causal next health risks to die after medical mistakes - All these cases should end annually with ignoring of the Czech Justice Courts, supervising Criminal Police CZ, supervising from State Penalty Offices CZ - and survivors or heavily crippled patients of the Czech Republic should receive from the responsibly Health instance CZ of the Providers nets of Health Services of the Czech Republic - approximately there are ignored 3 million compensation for financial satisfaction per 1 case per annum.

The total should therefore be a probable compensation in the astronomical annual amount yearly - 50 thousand persons CZ x 3 millioncrowns-theresultis $15 \times 10 \times 10 \times 10 \times 10 \times 10 \times 10 \times 10 \times 10 \times 10 \times 10$ = 150 milliard CZK / year!!! Thus, in the Czech Republic's national income about Sum CZK 330 Milliard, almou nearly half of the annual income is a waste of medical work. This is for the Healthcare of the Czech Republic, for the Provider of Health Services and their 
Employees, for the Judiciary CZ, for the State Budget of the Czech Republic, for the Criminal Police of the Czech Republic, for the Public Prosecutor's Office of the Czech Republic unprivileged by national, political.

However, we have a very novel solution in the Czech Republic whether you are an individual patient crippled and dying for legal or illegal medical mistakes very Cheap: All fatal cases will be placed in the category of "Unwanted inevitable medical and legal results of medical processes" with the unique cover false slogan LEGE ARTIS CZ. It is similar as a Italy Mafia with more strong laws, more servos as a OMERTA, who has taken a keen interest in all the injured patients in the medical, security, criminal and custody organizations: You are either a healthy, unnecessarily frozen or unnecessarily dying patient in the Czech Republic - but absolutely under the monotonic motto of observing Medical cases with false wisdom declination the principles of LEGE ARTIS CZ. So that any private truth criminalist evidence of Patients CZ, when that you are the Victim of a criminal way of providing medical health care will come out monotonously: You will almost never receive adequate financial justice satisfaction, because it is only derived of your preliminary "informed Patient consent" to planned risky and probably often including very technically illegal medical practice with Medical Devices, often with explicitly wrongly misused The Medical Devices- you have only one direction right Cementary route: sooner or later, without any patient comments to Court dealing CZ: to die without delay as a false result of the absolutely indifference responsible medical work "LEGE ARTIS CZ" with content many fatal explicit illegal technical partial medical mistakes [1-3].

Annual unnecessary severe mutilation of at least about 40 to maybe perhaps 50,000 patients in the Czech Republic with a much earlier causal death - this is a pre-agreed probable loss of life and health of the Czech Patients, which is the number of deaths and astronomically large national economic losses similar to the lives of Victims of the secret national continual war Physicians CZ - against their own patients in the Czech Republic, often absolute out of legal technical usage Medical Devices in hospital net CZ in regards to Technician Requirements of Laws EU/CZ.

\section{The Perspective for Solutions to Limit and to Prevency the Mass Repeated Medical Mistakes in OECD}

I know namely reliable coherent scientific processing to limit the Mass repeated similar medical mistakes with more efficiency sharing the best medical experiences only as perfect redefined scientific principles "LEGE ARTIS CZ" - with more effective managing medical workflow with more effective usage samplings, clustering, validated medical processing, continual testing elementary partial medical activities of partial medical processing step by steps“ with more efficiency implanting Artificial intelligence, with more regards to Technician requirements of Laws EU/CZ for usage Medical Devices - with acquired my decision making method S_T_A_R_S in daily medical workflow - see the Literature Antonín Cuc: The Utility model 21532 CZ 2010, Czech Office for Industrial
Laws. The Equipment for Retrieval and Search of sufficient statistic information to repeated similar strategic decision making with risk and computer support "the opened Sources to usage for Medicine US since April 17, 2017!

As a scientist, I am well educated in the field of Cybernetics and Statistics and in the field of $\mathrm{H}+\mathrm{S}$ for Medical Devices, Technician requirements of Laws EU/CZ for legal processing usage Medical Devices in Providers Health care nets!

\section{The précised and Redefined Logical Criminalist Defini- tion Lege Artis Medical Processing in Health Care OECD}

No medical process can be truthfully assessed as complying with the principles of "Lege artis OECD“ or „Based evidence medicine OECD“ - if it contains at least One partial illegal technical medical activity!

For example, violation of the Technical Requirements of the Laws on the Legal Safe Use of Medical Devices, for example in contravention of the Technical Requirements of EU / the use of Medical Devices, contrary to the requirements of related harmonized European standards, contrary to the instructions of the manufacturers of medical devices and contrary to the certified use of their installation and measuring instruments, contrary to the obligation to prevent known hazards declared in the Protocols on Medical Devices as products with use management conformity assessment rules "CE".

\section{The Logical Substantiation in Medical Processing OECD}

In the Binary Logics so as in the Criminalist Logics for the conjunctions partial mixed procedural phenomenon's with evaluating True, False - there are sum resulting evaluation the coherent sequential processing always resulting in evaluation $\mathrm{F} \mathrm{A}$ L S E, when there are occurrence at least the One partial unit with evaluation with partial well criminal evidenced FALSE, definitely!

I am just needless dying Patient CZ because the implanting processing set Total Hip Arthroplasty since November 13, 2007 contained many illegal processing medical mistakes contrary functional assembling product processing for set THA Bicontact $\mathrm{S}$, no cemented, nominal dimension $13 \mathrm{~mm} \mathrm{~N}$, B.Braun Germany

- with false coaxial ties between the metallic Stem and my right femoral bone in the Surgery hall without preliminary Clinic Plan, with illegal declination coaxial ties 13,68 grads in sagittal Direction, out of acceptable assembling tolerance +/- 1 grad - The post operational first RTG images from date November 16, it was the sufficient criminal evidences about false illegal placement the spice the Stem in coordinate $\mathrm{Xi}, \mathrm{Yi}, \mathrm{Zi}$ - out of the firm installing radiologic Masks - but it should be controlled by the Laws and by the product ovoid on the Orthopaedic screen with the same scaling.

The wisdom false Court Medical Message from the Knowing Medical Institute - The Central Army Hospital Prague, CZ No. 36 C 181/2009-123 since the March 27, 2012 defined all Medical Orthopaedic Processing in Limits Lege Artis CZ, The fatal unhappy was defined not as Diagnose Fausse route stem on the Orthopaedic Surgery Hall - but as the results of the false medical Hypotheses in 
Complot of the Radiologic, Orthopads Doctors from the Orthopady Clinic and from the Knowing Medical Institute as Post operational tragic Event by Patient fallen", despite such substitutions in truth Criminal traceing, Radiology, Geometry 3 D, Health Patient Documentation EHRs.

I laid down my life so that you and your physicians and technicians can work together in a responsible manner and in the real truth of God and in the same truth of the criminalist evidences.

I became an unnecessary Merthyr of human Stupidity and irresponsibility that threatens humanity and the patients of the Czech Republic who are denied the Constitutional Human Rights of the Czech Republic: for life, for a fair Court trials, for legal health care CZ. I believe that Medicine US will never accept the falsity of the current approaches of "LEGE ARTIS CZ", as now submitted to the world public by the Czech courts, the Criminal Police of the Czech Republic, the network of the State Prosecutor's Offices of the Czech Republic.

I am just placing the principal private RTG images for Forensic reconstruction Crash of set THA Bicontact $S$, no cemented in Geometry 3 D since date November 13, 2007 on the Orthopaedic Surgery Hall of the Regional Hospital Mladá Boleslav. Most of Patients with similar Crash are dying in duration since 3 till 7 days after overlooked FAUSSE ROUTE STEM, I was reoperation till 17 days after Poly trauma on the Surgery Hall, when the preoperational THA processing was realised in the same profile of Surgeon catting as in first THA, but the Spice of the Stem was created met he blooding and full plegic dysfunction Nervus is achidici with destructions my structure muscles in right calf, I am just frequential happened fallen with risk the repeated breaking the proximal femoral bone with just $8 \mathrm{x}$ worse probabilities and I am dying earlier about many years as other Patients CZ in Cluster with right legal first THA surgery.

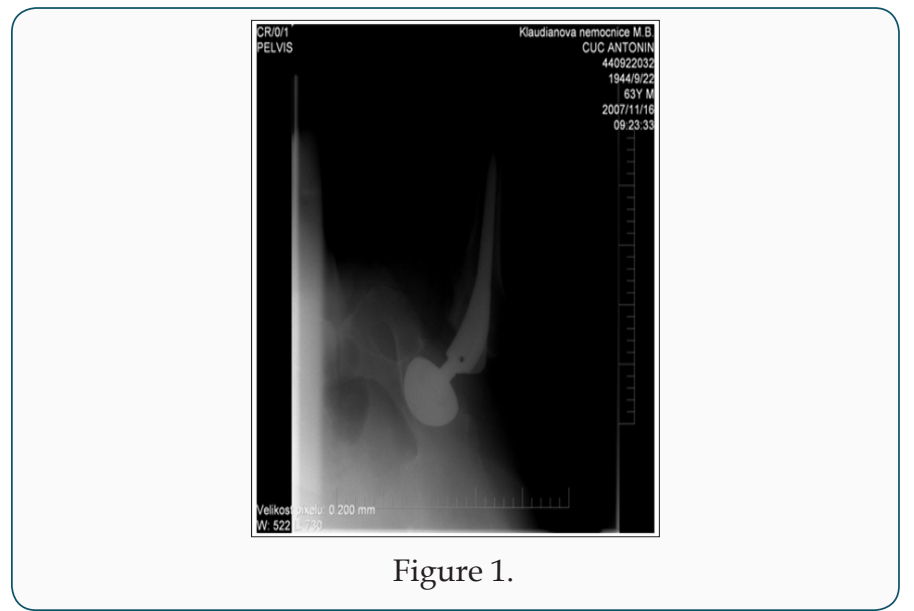

My Orthopads, my Judge, the forensic doctors from the Knowing Medical Institute CZ, Departments of Criminal Police CZ, State Penalty Offices CZ are smiling to my nearly Death within forced me many growing casual orthopaedic and leukemic heavy injuring LEGE ARTIS CZ (Figure 1). The virtual „Shorten of the Length the Axes of metallic Stem "It is caused the false placement with fatal declination in sagittal Direction in angle 13, 68 grads, there are false installing position of the spice Stem on coordinates Xo, Yo, Zi - it is illegal „to observing the RTG image in hands and by intuitive views", when the Orthopads should taken the Orthopaedic screen and comparison the placement the Spice contrary firm radiologic Mask for the stem!

The Doctors said by illegal daily habits: We are working Lege artis, only a few orthopaedic patient are sometimes legal dying! The Criminal police CZ gave legal agreements so as the Knowing Medical institute CZ too - The mortal injured Patient CZ on the Prosector Hall haven't commentaries! We are dying needless and very Cheap and frequently in CZ, always Lege Artis CZ (Figure 2). This is the Image from date November 28, 2007 too, this is forensic nonsense to prented this Criminal traceing could be realised as Patient fatal post operational happened! The last moving of the Stem was realised in Surgery hall November 13, 2007 in Regional Hospital Mladá Boleslav CZ.

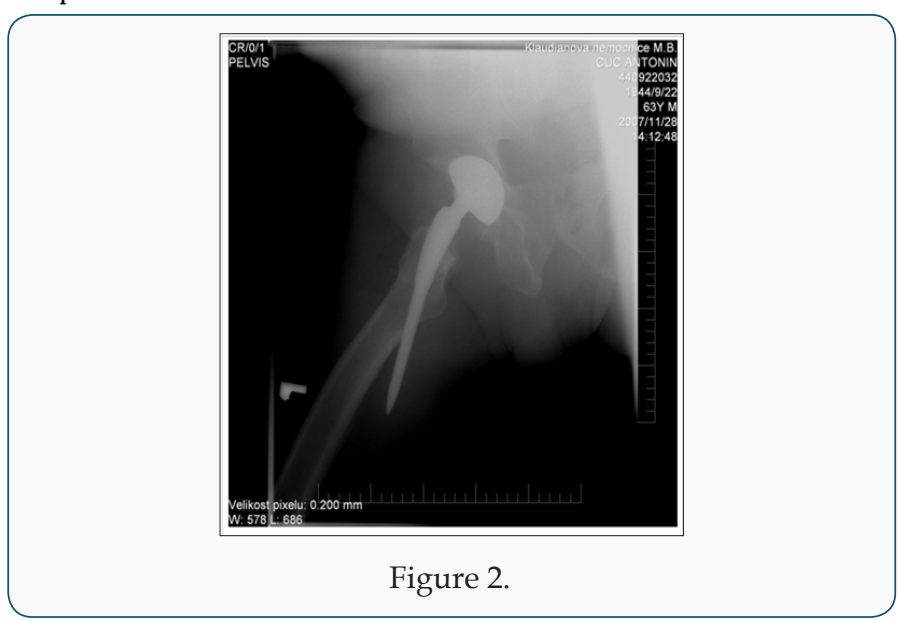

In Court trials CZ the Judge could believe for medical illegal Stupidities each of workaday. No Protests from Patients CZ are accepted in legal care for Constitutional Human Rights CZ by Ombudsman CZ- despite me is the Sate investigator for occupational mortalities in Branche Medical Devices. My Death is very awaiting CZ Events, like a public Execution of a disagreeable world Scientist in $21^{\text {st }}$ Century (Figure 3).

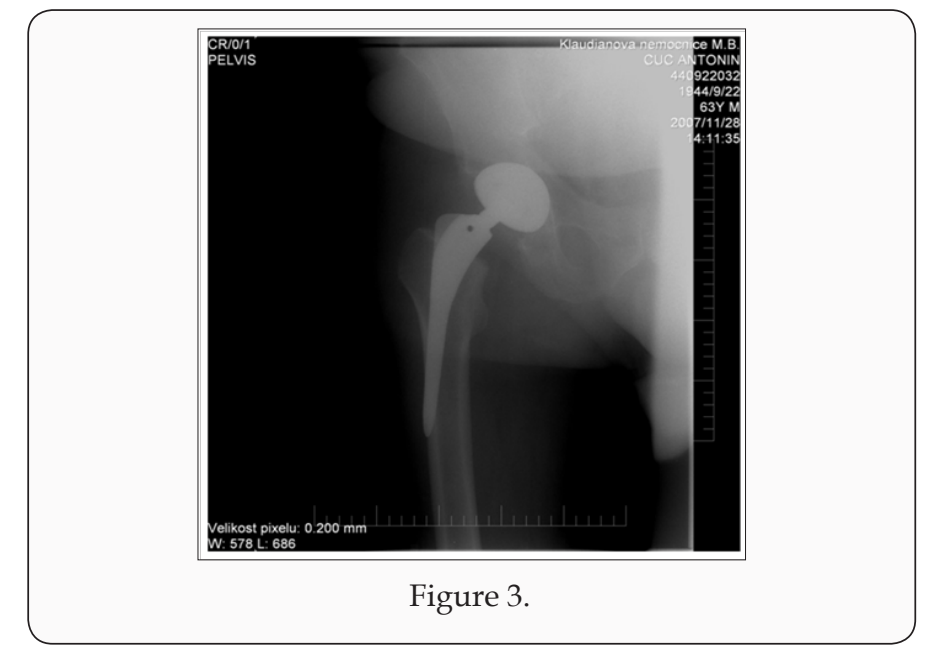




\section{Reference}

1. Cuc Antonín (2010) The Equipment for Search and Retrieval sufficient statistic information to reuse for Mass similar repeated Decision Making with risks and computer support. The Utility Model 21532 CZ 2010, Czech Office for Industrial Laws.

2. (2009) Health Orthopaedic Documentation Antonín Cuc for plaint the civic Court trial on the Regional Court Prague No. 36 with Court Medical Message No 36.
3. (2012) The Standpoint of the Complaint Antonín Cuc to Court Medical Message in letter to Judge JU Dr. Vojtěch Cepl. The Judgement No $36 \mathrm{C}$ 181/2009-221.

\section{(c) (1) \\ This work is licensed under Creative Commons Attribution 4.0 License}

To Submit Your Article Click Here:

Submit Article

DOI: 10.32474/OSMOAJ.2018.01.000109

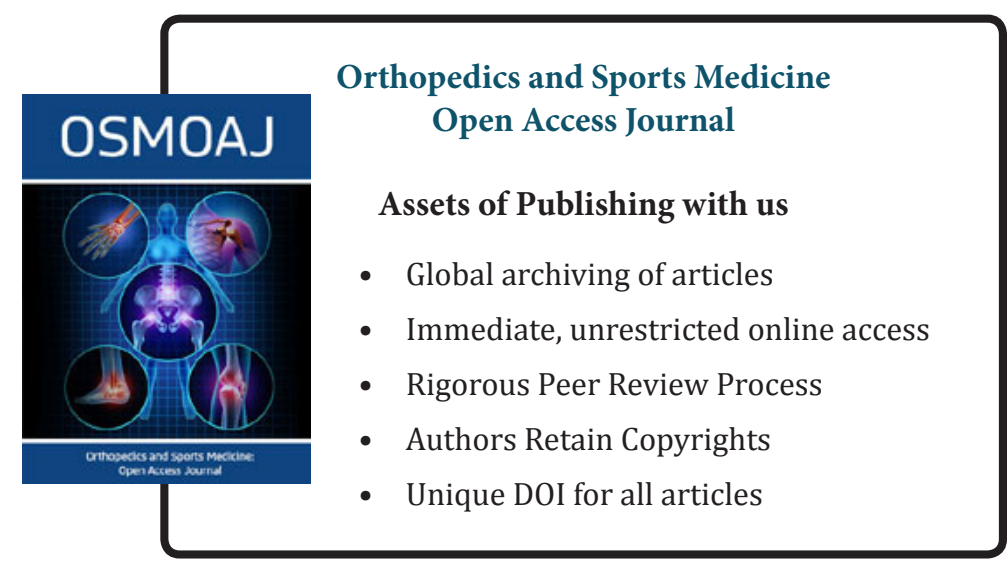

